\title{
PAKAN IKAN OTOMATIS BERBASIS SMS
}

\author{
Imam Taufiqurrahman ${ }^{1}, \mathrm{M}$ Aris Risnandar ${ }^{2}$, Andri Ulus R ${ }^{3}$, Linda Faridah ${ }^{4}$ \\ Universitas Siliwangi (Teknik Elektro, Universitas Siliwangi, Tasikmalaya, Indonesia) ${ }^{1}$ \\ Afiliasi Penulis Kedua (Jurusan/Prodi, Institusi, Kota, Negara) ${ }^{2}$ \\ email: (imamtaufiqurrahman@unsil.ac.id)
}

\begin{abstract}
Entrepreneurship as one of the work-support solution to fulfill the living expenses. One of the entrepreneurships prevalently pursued in Indonesia is fish farming. Some common problems that often occur is the lack of fund and unable to pay wages of the workers while we were busy dealing with the office hours. The feed was one of the important factors to be considered in fish farming. A proper feeding administered will determine the success of fish farming. In this final project it was generated a system that was able to discharge the fish feeding automatically with the commands delivered via SMS. This system consisted of inputs, processes and outputs. The inputs employed Wavecom M1306b and the outputs generated DC motor and Wavecom M1306b when the data process was administered by using ATmega 8535 microcontroller. Soon after the wavecom received a command message (SMS), the order was delivered to the microcontroller to be processed. If the format fits well, the microcontroller will send an order to activate the DC motor, and further the microcontroller will ask the wavecom to reply a confirmation message as the order has been executed. However if the format of the message sent did not match, the reply turned out to be "Format salah". From the analysis, it emerged the system was able to work properly as what was said in the design specifications.
\end{abstract}

Keywords: Mikrokontroler ATmega8535, Motor DC, Pakan, SMS, Wavecom M1306b.

\begin{abstract}
Abstrak
Wirausaha merupakan salah satu solusi penunjang pekerjaan dalam memenuhi kebutuhan hidup. Salah satu jenis wirausaha yang populer dilakukan di Indonesia adalah budidaya ikan. Permasalahan yang sering terjadi yaitu dengan minimnya modal, kita tidak dapat membayar upah pekerja untuk budidaya ikan selagi kita sibuk dengan jam kerja di kantor. Pakan merupakan salah satu faktor yang perlu diperhatikan dalam budidaya ikan. Pemberian pakan yang tepat akan menentukan keberhasilan budidaya ikan. Pada penelitian ini dihasilkan sebuah sistem yang mampu memberikan pakan ikan secara otomatis dengan perintah yang disampaikan melalui SMS. Sistem ini terdiri dari bagian input, proses dan output. Bagian input yaitu Wavecom M1306b, Bagian output terdiri dari motor DC dan Wavecom M1306b sedangkan pemrosesan data menggunakan Mikrokontroler ATmega8535. Ketika Wavecom menerima SMS, kemudian perintah akan disampaikan ke Mikrokontroler untuk diproses. Jika format sesuai, Mikrokontroler akan mengirim perintah untuk menggerakan motor DC, selanjutnya Mikrokontroler akan memerintahkan Wavecom untuk membalas SMS sebagai konfirmasi telah dijalankanya printah tersebut. Namun ketika format SMS yang dikirim tidak sesuai, maka SMS akan dibalas "Format Salah". Dari hasil pengujian yang dilakukan sistem ini dapat bekerja sesuai dengan spesifikasi perancangan.
\end{abstract}

Kata Kunci: DC Motor, Feed, Microcontroller ATmega8535, SMS, Wavecom M1306b.

\section{PENDAHULUAN}

Dewasa ini bekerja seringkali dirasa tidak dapat memenuhi kebutuhan hidup seseorang, Banyak yang mengambil solusi berwirausaha sebagai penunjang pekerjaan dalam memenuhi kebutuhan hidup. Namun solusi itu tidak dapat dilakukan oleh semua orang, dikarenakan tidak semua orang memiliki modal cukup untuk membangun wirausaha yang dapat berjalan sendiri dan dapat menghasilkan passif income. Salah satu jenis wirausaha yang populer dilakukan di Indonesia adalah budidaya ikan. Permasalahan yang sering terjadi yaitu dengan minimnya modal, kita tidak dapat membayar upah pekerja untuk budidaya ikan selagi kita sibuk dengan jam kerja di kantor.

Salah satu hal penting dalam budidaya ikan yaitu pemberian pakan yang tepat [1]. Dengan kesibukan jam kantor dan tidak adanya pekerja yang melakukan hal tersebut tentulah menjadi masalah bagi kita yang akan berwirausaha budidaya ikan dengan modal yang minim. Dengan diciptakan sistem otomatis yang dapat dikendalikan dengan ponsel melalui Short Message Service (SMS) untuk memberikan pakan pada ikan kita tentulah dapat menjawab masalah itu. Diharapkan dengan adanya sistem ini dapat menjadi solusi bagi pekerja yang akan berwirausaha budidaya ikan.

Dalam penelitian yang dilakukan Ratna Desta Wahyu Ningtias, telah dirancang sebuah alat menggunakan Mikrokontroler AT89S52 untuk memberikan pakan secara teratur selama 8 jam dengan takaran yang sudah di tentukan
[2]. Dalam penelitian yang dilakukan Arif Khoirudin, telah dirancang sebuah alat menggunakan Mikrokontroler ATmega8535 untuk memberikan pakan ikan secara otoamtis dengan takaran yang diatur dengan push button [3]. Dalam penelitian yang dilakukan Ananda Darsono, telah dirancang sebuah alat menggunakan Mikrokontroler ATmega8535 untuk memberikan pakan ikan melalui SMS [4]. Beberapa penelitian di atas, menjadi bahan pertimbangan untuk mengembangkan sebuah sistem yang digunakan untuk memberikan pakan ikan secara otomatis. Dimana pada sistem tersebut belum terdapat variasi takaran pakan yang akan diberikan dan belum terdapat konfirmasi apabila proses pemberian pakan telah dilaksanakan. Penelitian ini bertujuan untuk membuat sistem pemberi pakan otomatis melalui SMS yang memiliki beberapa variasi takaran pakan dan memiliki konfirmasi apabila proses pemberian pakan telah dilaksanakan.

\section{KAJIAN PUSTAKA}

\section{A. Pakan Ikan}

Pakan ternak, salah satu hal paling penting bagi para usahawan dan orang-orang yang bekerja di bidang peternakan. Pakan ternak sendiri merupakan makanan khusus untuk hewan ternak peliharaan kita seperti, ayam, sapi, kambing, ikan, dll. Bagi para usahawan ternak, pakan sangat berpengaruh terhadap kelangsungan hewan ternak kita, dengan komposisi pakan yang tepat tentunya akan 
membuat produksi peternakan kita jadi lebih baik dan maksimal hasilnya.

Pakan menjadi faktor utama usaha peternakan. Tersedianya pakan dari segi kualitas, kuantitas dan kontinuitas sangat berpengaruh terhadap keberhasilan usaha peternakan. Dalam penelitian yang dilakukan Teuku Fadlon Haser, Amin Setiawan, dan Intan Rahima Sary Penelitian mengenai Pengaruh Jumlah Pemberian Pakan terhadap Pertumbuhan Benih Ikan Nila Merah di Laboratorium Departemen Agribisnis Perikanan, PPPPTK Pertanian (VEDCA), Cianjur. Penelitian ini dilakukan untuk mengetahui seberapa besar pengaruh jumlah pemberian pakan yang berbeda-beda terhadap pertumbuhan benih ikan nila. Hasil penelitian menunjukkan bahwa perlakuan pemberian pakan sebesar $5 \%$ menghasilkan laju pertumbuhan harian yang terbaik sebesar $4,15 \%$, dibandingkan dengan pemberian pakan sebesar $2 \%, 3 \%$, dan $4 \%$.

\section{B. Mikrokontroler ATMEGA8535}

Prosesor yang digunakan sebagai pengendali utama sebuah sistem adalah 8 bit mikrokontroler dari keluarga AVR, yaitu ATMEGA8535. Alasan penggunaan mikrokontroler ini adalah karena harga yang relatif murah, mudah diperoleh, kemudahan dalam pemrograman, dan fitur-fitur menarik yang dimilikinya. Beberapa karakteristik dan fitur yang dimiliki mikrokontroler ATMEGA8535 antara lain Resolusi data 8 bit, RISC arsitektur, $8 \mathrm{~K}$ byte In System Programmable Flash, 512 Bytes EEPROM, 512 Bytes SRAM internal, 8 channel, 10 bit resolusi ADC, 4 channel PWM, 2 timer/counter 8 bit, 1 timer/counter 16 bit, Osilator internal yang dikalibrasi, Internal dan eksternal sumber interrupt, 6 mode sleep. ATMEGA 8535 memiliki struktur bagian sebagai berikut Saluran I/O 32 buah, yaitu Port A, Port B, Port C, dan Port D, tiga buah timer/counter dengan kemampuan perbandingan, CPU yang terdiri atas 32 buah register, memori Flash sebesar $8 \mathrm{~kb}$ dengan kemampuan read while write, unit interupsi internal dan eksternal, port antarmuka SPI, EEPROM sebesar 512 byte yang dapat diprogram saat operasi, antarmuka komparator analog, port Usart untuk komunikasi serial. Dengan konfigurasi pin seperti pada gambar 1 .

\begin{tabular}{|c|c|c|c|c|c|c|}
\hline (ХСК/ТО) & PBO ᄃ & 1 & 40 & 巴 & PAO & $(A D C D)$ \\
\hline (T1) & PB1 드 & 2 & 39 & 巴 & PA1 & (ADC1) \\
\hline (INT2/AINO) & PB2 드 & 3 & 38 & 曰 & PA2 & (ADC2) \\
\hline (OCO/AIN 1$)$ & PB3 ᄃ & 4 & 37 & 曰 & PA3 & (ADC3) \\
\hline (5S) & PB4 C & 5 & 36 & 曰 & PA4 & (ADC4) \\
\hline (MOSI) & PB5 ㄷ & 6 & 35 & 曰 & PA5 & (ADC5) \\
\hline (MISO) & PB6 드 & 7 & 34 & 巴 & PAS & (ADC6) \\
\hline$(\mathrm{SCK})$ & PB7 든 & 8 & 33 & 曰 & PA7 & (ADC7) \\
\hline & ESET ㄷ & 9 & 32 & 巴 & ARE & \\
\hline & VCC 드 & 10 & 31 & 巴 & GND & \\
\hline & GND ᄃ & 11 & 30 & 曰 & AVC & \\
\hline & TAL 2 C & 12 & 29 & 巨 & PC7 & (TOSC2) \\
\hline & TAL1 C & 13 & 28 & 巳 & PC6 & (TOSC1) \\
\hline (RXD) & PDO ᄃ & 14 & 27 & 曰 & PC5 & \\
\hline$(T \times D)$ & PD1 ㄷ & 15 & 26 & 巨 & $\mathrm{PC} 4$ & \\
\hline (INTO) & PD2 든 & 16 & 25 & 巨 & $\mathrm{PC}_{3}$ & \\
\hline (INT 1$)$ & $\mathrm{PD} 3 \mathrm{C}$ & 17 & 24 & 口 & $\mathrm{PC2}$ & \\
\hline (OC1B) & PD4 ᄃ & 18 & 23 & 曰 & PC1 & (SDA) \\
\hline$\left(O C_{1 A}\right)$ & PD5 ㄷ & 19 & 22 & 曰 & $\mathrm{PCO}$ & (SCL) \\
\hline (ICP1) & PD6 5 & 20 & 21 & 曰 & PD7 & $(\mathrm{OC} 2)$ \\
\hline
\end{tabular}

Gbr 1. Konfigurasi pin ATMEGA8535

\section{Wavecom $1306 b$}

Wavecom merupakan salah satu jenis modem GSM yang memiliki output db 15 atau db 9 dengan level tegangan RS232. Modem ini seringkali digunakan dalam pengintegrasian sistem GSM dan mikrokontrol dikarenakan cukup mudah dalam pengaplikasiannya. Salah satu jens modem Wavecom yaitu $1306 \mathrm{~b}$ yang dipakai dalam perancangan penelitian ini,bentuk fisik dari WAvecom $1306 \mathrm{~b}$ dapat dilihat pada gambar 2 .

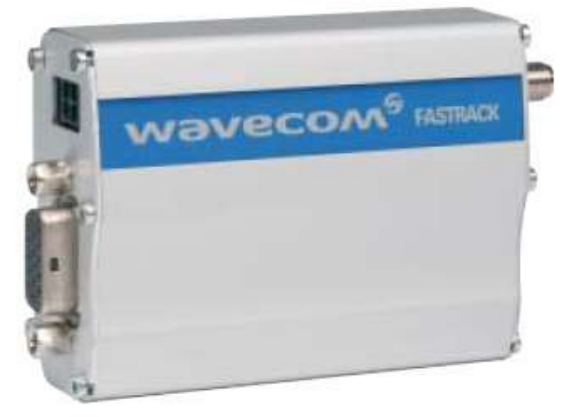

Gbr 2. Modem Wavecom 1306b

\section{D. $\operatorname{Max} 232$}

MAX232 merupakan salah satu jenis IC yang memenuhi semua spesifikasi standar EIA-232-E. IC MAX232 hanya membutuhkan power supply 5V sebagai catu daya. IC MAX232 di sini berfungsi untuk merubah level tegangan RS232 pada Wavecom menjadi level tegangan TTL / CMOS. IC MAX232 terdiri atas tiga bagian yaitu dual charge-pump voltage converter, driver RS232, dan receiver RS232. Konfigurasi pin dari IC MAX232 terdapat pada gambar 3.

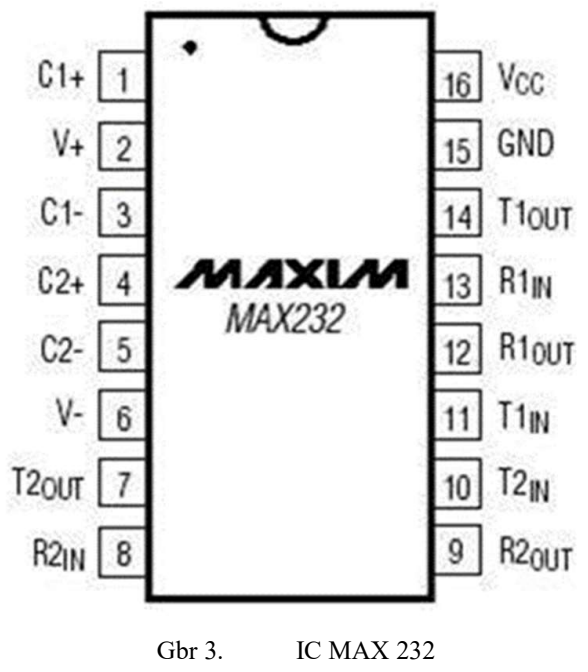

III. METODE

\section{A. Tahapan Pelaksanaan}

Tahapan pelaksanaan dalam Penelitian ini dapat dilihat pada Gambar 4, dimulai dengan studi literatur dari beberapa sumber diantaranya, penelitian yang dilakukan Ratna Desta Wahyu Ningtias, telah dirancang sebuah alat menggunakan Mikrokontroler AT89S52 untuk memberikan pakan secara teratur selama 8 jam dengan takaran yang sudah di tentukan [2]. Dalam penelitian yang dilakukan Arif Khoirudin, telah dirancang sebuah alat menggunakan Mikrokontroler ATmega8535 untuk memberikan pakan ikan secara otoamtis dengan takaran yang diatur dengan push button [3]. Dalam penelitian yang dilakukan Ananda Darsono, telah dirancang 
sebuah alat menggunakan Mikrokontroler ATmega8535 untuk memberikan pakan ikan melalui SMS [4] dan penelitian yang dilakukan Randi Anggit Wibisono, telah dirancang bangun alat penebar pakan ikan dengan menggunakan gaya sentrifugal tipe apung [5]. Dari beberapa

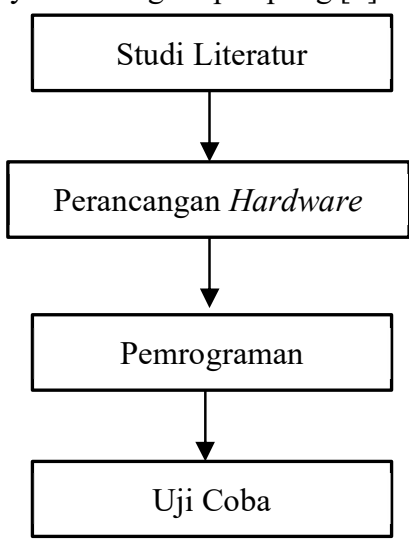

sumber tersebut didapatkan saran-saran dalam merancang alat dalam penelitian ini. kemudian dilanjutkan dengan perancangan spesifikasi sesuai diagram blok sistem kerja, perancangan hardware, pemograman dan uji coba terhadap sistem yang telah dibuat.

Gbr 4. Tahapan Peaksannan Penelitian

\section{B. Rancang Bangun Hardware}

Rancang bangun hardware dilakukan sesuai diagram blok sistem pakan ikan otomatis melalui SMS yang ditunjukan pada gambar 5. Skematik rangkaian alat pemeberi pakan ikan otomatis ditunjukan pada gambar 3 . Saat Wavecom menerima SMS, Wavecom akan menyampaikan SMS ke mikrokontroler ATMEGA8535 dan isi sms tersebut diproses oleh mikrokontroler. Jika SMS sesuai dengan format yang telah ditentukan, maka mikrokontroler akan mengirimkan sinyal pada relay untuk menjalankan motor DC dengan waktu yang disesuaikan dengan format SMS. Setelah selesai melaksanakan perintah mikrokontroler akan memerintahkan Wavecom untuk mengirimkan SMS konfirmasi. Namun jika isi SMS tidak sesuai dengan format maka mikrokontroler akan memerintahkan Wavecom untuk mengirim SMS konfirmasi yang berisi "Format salah".

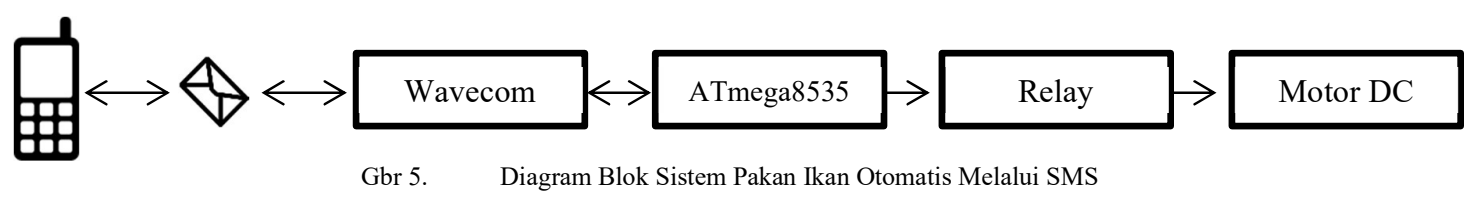

\section{Pemrograman}

Program yang akan diunduh ke dalam mikrokontroler, dibuat berdasarkan diagram alir (flow chart) yang ditunjukan oleh gambar 6 


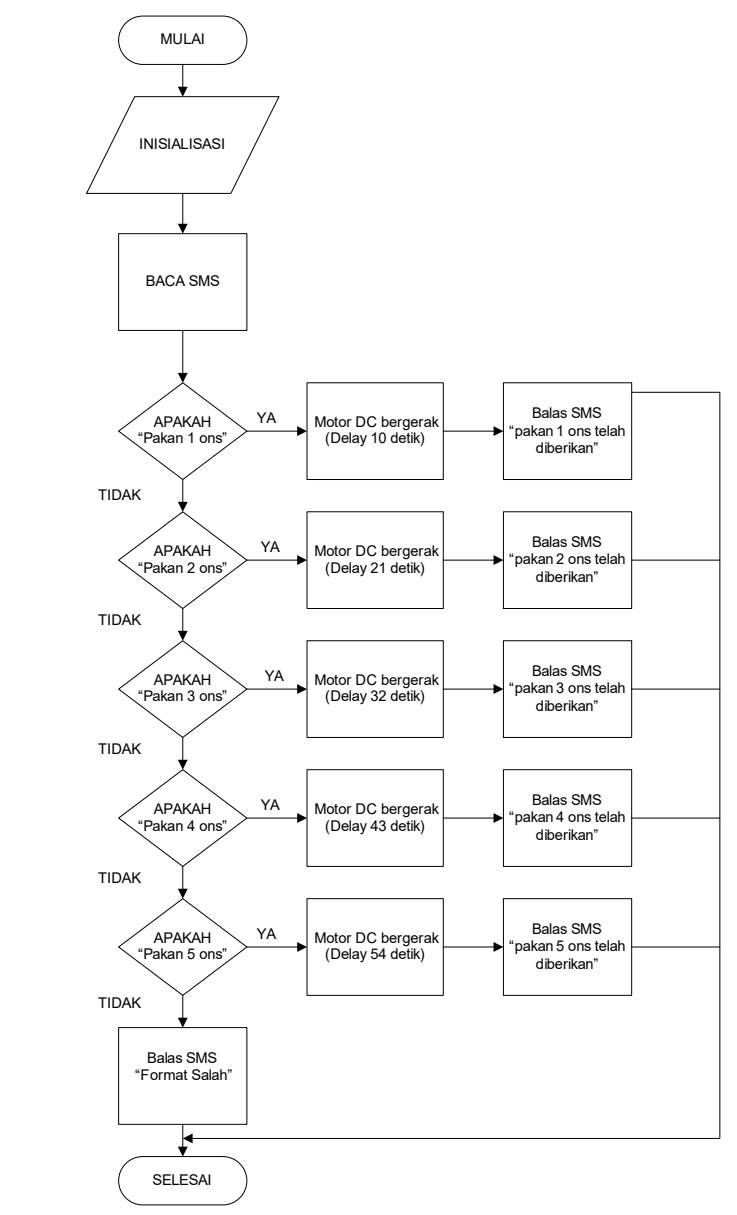

Gbr 6. flow chart Sistem Pakan Ikan Otomatis Melalui SMS

\section{HASIL DAN PEMBAHASAN}

\section{A. Hasil Rancang Bangun}

Hasil rancang bangun dari sistem pakan ikan otomatis melalui SMS, sesuai dengan spesifikasi yang dirancang yaitu, kemampuan menampung pakan $1,2 \mathrm{Kg}$, mempunyai 5 jenis perintah variasi takaran pakan yang diberikan yaitu, pakan 1-5 ons, mengirimkan SMS konfirmasi apabila proses pemberian pakan telah dilaksanakan, dan dimensi alat (panjang $(\mathrm{cm}) \times$ lebar $(\mathrm{cm}) \times$ tinggi $(\mathrm{cm})$ ) mikrokontroler $14,5 \times 9,5 \times 5,2$, Wavecom $10 \times 5,5 \times 6$, Penampung pakan $35 \times 25 \times 85$.Gambar 7 menunjukan bentuk fisik dari alat pakan ikan otomatis melalui SMS, dan gambar 8 menunjukan bentuk fisik penampung pakan ikan.

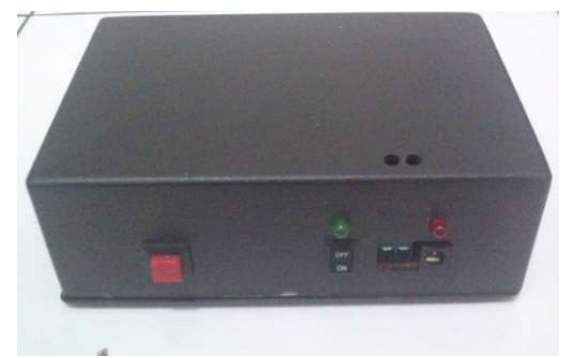

Gbr.7. Alat Pakan Ikan Otomatis Melalui SMS



Gbr.8.

Penampung Pakan Ikan

\section{B. Hasil Pengujian}

pengujian dilakukan pada perangkat keras sistem pemberi pakan ikan otomatis melalui SMS yaitu Pengujian ketepatan takaran pemberian pakan ikan. Pada pengujian ini motor digerakan dengan waktu yang telah ditentukan untuk menjatuhkan pakan seperti yang diperintahkan. Pegujian selanjutnya yaitu pengujian berjalannya SMS konfirmasi ketika proses pemberian pakan telah dilakukan. 
Tbl 1. Pengujian Pengujian pemberian pakan ikan dengan perintah 1-5 ons

\begin{tabular}{|c|c|c|c|}
\hline No. & $\begin{array}{c}\text { Pakan yang } \\
\text { diharapkan (gram) }\end{array}$ & $\begin{array}{c}\text { Pakan yang } \\
\text { dikeluarkan (gram) }\end{array}$ & $\begin{array}{c}\text { Error } \\
(\%)\end{array}$ \\
\hline 1 & 100 & 95 & 5 \\
\hline 2 & 100 & 100 & 0 \\
\hline 3 & 100 & 100 & 0 \\
\hline 4 & 100 & 100 & 0 \\
\hline 5 & 100 & 100 & 0 \\
\hline 6 & 100 & 105 & 5 \\
\hline 7 & 100 & 95 & 5 \\
\hline 8 & 100 & 95 & 5 \\
\hline 9 & 100 & 105 & 5 \\
\hline 10 & 100 & 100 & 0 \\
\hline 11 & 200 & 200 & 0 \\
\hline 12 & 200 & 200 & 0 \\
\hline 13 & 200 & 195 & 2,5 \\
\hline 14 & 200 & 195 & 2,5 \\
\hline 15 & 200 & 200 & 0 \\
\hline 16 & 200 & 200 & 0 \\
\hline 17 & 200 & 200 & 0 \\
\hline 18 & 200 & 195 & 2,5 \\
\hline 19 & 200 & 195 & 2,5 \\
\hline 20 & 200 & 200 & 0 \\
\hline 21 & 300 & 305 & 1,7 \\
\hline 22 & 300 & 300 & 0 \\
\hline 23 & 300 & 305 & 1,7 \\
\hline 24 & 300 & 295 & 1,7 \\
\hline 25 & 300 & 300 & 0 \\
\hline 26 & 300 & 305 & 1,7 \\
\hline 27 & 300 & 295 & 1,7 \\
\hline 28 & 300 & 300 & 0 \\
\hline 29 & 300 & 300 & 0 \\
\hline 30 & 300 & 290 & 3,3 \\
\hline 31 & 400 & 405 & 1,2 \\
\hline 32 & 400 & 400 & 0 \\
\hline 33 & 400 & 390 & 2,2 \\
\hline 34 & 400 & 395 & 1,2 \\
\hline 35 & 400 & 390 & 2,2 \\
\hline 36 & 400 & 405 & 1,2 \\
\hline 37 & 400 & 395 & 1,2 \\
\hline 38 & 400 & 395 & 1,2 \\
\hline 39 & 400 & 390 & 2,2 \\
\hline 40 & 400 & 400 & 0 \\
\hline 41 & 500 & 505 & 1 \\
\hline 42 & 500 & 495 & 1 \\
\hline 43 & 500 & 500 & 0 \\
\hline 44 & 500 & 500 & 0 \\
\hline 45 & 500 & 500 & 0 \\
\hline 46 & 500 & 495 & 1 \\
\hline 47 & 500 & 505 & 1 \\
\hline 48 & 500 & 505 & 1 \\
\hline
\end{tabular}

\begin{tabular}{cccc}
\hline 49 & 500 & 500 & 0 \\
\hline 50 & 500 & 510 & 2 \\
\hline $\begin{array}{l}\text { jum } \\
\text { lah }\end{array}$ & & 32 \\
\hline Rata-rata & & 0.64 \\
\hline
\end{tabular}

Dari tabel 1 dapat terlihat error pemberian pakan ikan dengan menggunakan delay pada motor memiliki kesalahan rata-rata $0,64 \%$. dengan demikian dapat dinyatakan bahwa perintah yang dikirim dijalankan dengan baik.

Tbl 1. Pengujian SMS Konvirmasi

\begin{tabular}{cccc}
\hline No. & $\begin{array}{c}\text { SMS } \\
\text { Perintah }\end{array}$ & SMS konfirmasi & Ket. \\
\hline 1 & Pakan 1 ons & Pakan 1 ons telah diberikan & Sesuai \\
\hline 2 & Pakan 2 ons & Pakan 2 ons telah diberikan & Sesuai \\
\hline 3 & Pakan 3 ons & Pakan 3 ons telah diberikan & Sesuai \\
\hline 4 & Pakan 4 ons & Pakan 4 ons telah diberikan & Sesuai \\
\hline 5 & Pakan 5 ons & Pakan 5 ons telah diberikan & Sesuai \\
\hline 6 & Beri pakan & Format salah & Sesuai \\
\hline
\end{tabular}

Dari tabel 2 dapat terlihat SMS konfirmasi sesuai dengan perintah yang diberikan. dengan demikian dapat dinyatakan bahwa perintah yang dikirim dijalankan dengan baik. Screen shoot dari hasil pengujian pada table 2 ditampilkan pada gambar 9 .

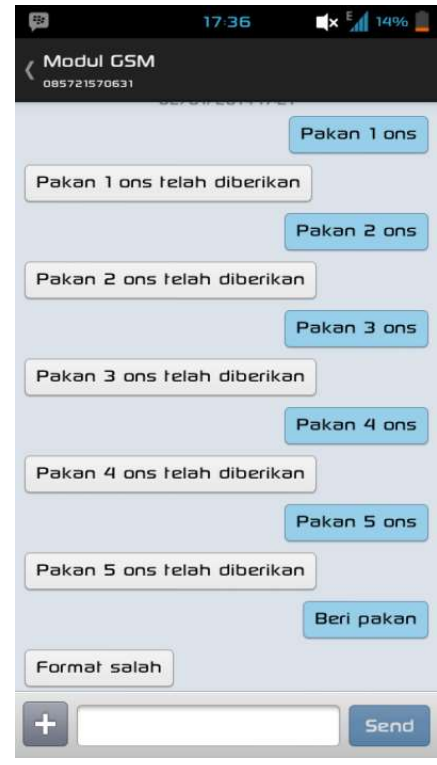

Gbr 9. Screen shoot Pengujian SMS konfirmasi

\section{KESIMPULAN}

Dari hasil pengujian yang dilakukan, sistem ini dapat bekerja sesuai dengan spesifikasi perancangan. Perintah pemberian pakan memiliki variasi takaran dan memberikan konfirmasi apabila perintah telah dilaksanakan. Kekurangan pada sistem ini yaitu belum adanya pemberitahuan kondisi jumlah pakan yang tersedia di tempat penampungan pakan. 


\section{REFERENSI}

[1] Teuku Fadlon Haser, Amin Setiawan, dan Intan Rahima Sary. (2012). Pengaruh Jumlah Pemberian Pakan terhadap Pertumbuhan Benih Ikan Nila Merah. Bandung: Universitas Padjajaran. [Online]. Tersedia: http://fpik.unpad.ac.id/archives/2391.

[2] Ratna Desta Wahyu Ningtias. (2010). Sistem Pengendalian Aquarium dan Pemberian Pakan Ikan Secara Otomatis Berbasis Mikrokontroler. Surabaya: Universitas Pembangunan Nasional.[Online]. Tersedia: http: eprints.upnjatim.ac.id/994/1/file_1.pdf.

[3] Arif Khoirudin Toufik Muttaqin. (2010). Sistem Penjadwalan Pakan Ikan Otomatis Berbasis Mikrokontroler ATmega 8535. Yogyakarta: STIMIK AMIKOM. [Online].

Tersedia: http://journal.amikom.ac.id/index.php/D3TI/article/vie $\mathrm{w} / 3865$.

[4] Ananda Darsono. (2010). Pemberi Makan Ikan Otomatis Untuk Aquarium Ikan Koi Dengan Media SMS Berbasis Mikrokontroler AVR ATMega8535. Jakarta: Universitas Gunadarma. [Online].Tersedia: http://library.gunadarma.ac.id/repository/view/7354/.

[5] Randi Anggit Wibisono (2018). Rancang Bangun Alat Penebar Pakan Ikan Dengan Menggunakan Gaya Sentrifugal Tipe Apung. [Online] Tersedia: http://digilib.unila.ac.id/32520/3/SKRIPSI\%20TANP A\%20BAB \%20PEMBAHASAN.pdf.



\section{BIOGRAFI PENULIS}

Imam Taufiqurrahman, lahir di Bandung pada tanggal 12 juni 1990 , saai ini bertugas sebagai staf pengajar di Jurusan Teknik Elektro,Universitas SIliwangi, bidang penelitian yang ditekuni saat ini adalah Otomasi, Robotika dan Sistem Cerdas.

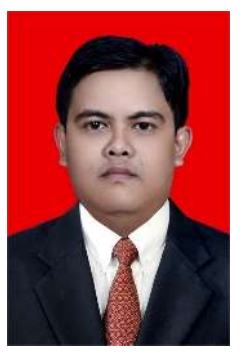

Muhammad Aris Risnandar, lahir di Ciamis pada tanggal 10 April 1988. Saat ini bertugas sebagai dosen di Jurusan Teknik Elektro, Universitas Siliwangi. Bidang penelitian yang ditekuni saat ini yaitu Sistem Tenaga Listrik dan Sistem Distribusi.

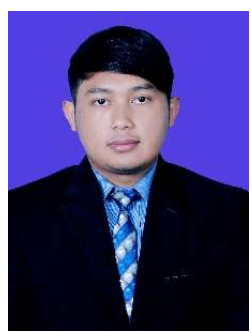

Andri Ulus Rahayu, lahir di Bandung pada tanggal 03 April 1989. Saat ini bertugas sebagai dosen di Jurusan Teknik Elektro, Universitas Siliwangi. Bidang penelitian yang ditekuni saat ini yaitu kendali, IoT, komputer.

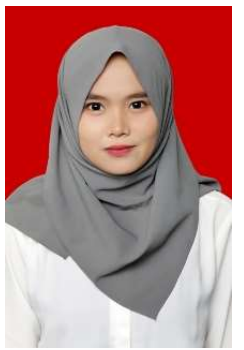

Linda Faridah, lahir di Bandung pada tanggal 17 Maret 1995. Saat ini bertugas sebagai dosen di Jurusan Teknik Elektro, Universitas Siliwangi. Bidang penelitian yang ditekuni saat ini yaitu Sistem Tenaga Listrik, renewable energy. 